\title{
EFEITO DA SEXAGEM E LINHAGENS SOBRE O DESEMPENHO E RENDIMENTO DE CARCAÇA DE FRANGOS DE CORTE
}

\section{EFFECT OF STRAINS AND SEXING ON PERFORMANCE AND CARCASS YIELD OF BROILERS}

\author{
Ivandro Api ${ }^{1}$ \\ Sabrina EndoTakahashi $1^{*}$ \\ Angélica Signor Mendes ${ }^{1}$ \\ Sandro José Paixão ${ }^{1}$ \\ Rosana Refati ${ }^{1}$ \\ Rasiel Restelatto ${ }^{1}$ \\ ${ }^{1}$ Universidadade Tecnológica Federal do Paraná, Dois Vizinhos, PR, Brasil \\ *Autora para correspondência - sabrinaendo@gmail.com
}

\section{Resumo}

Realizou-se este trabalho com o objetivo de avaliar o desempenho produtivo e o rendimento de carcaça de diferentes linhagens e sexagens de frangos de corte. Foram avaliadas 576 aves das linhagens Cobb, Ross e Hubbard, dispostas nas sexagem macho, fêmea ou misto, abatidas aos 45 dias de idade. Utilizou-se o delineamento inteiramente casualizado (DIC), num bifatorial 3 x 3 (linhagens x sexagem), com quatro repetições e 16 aves em cada tratamento. $O$ peso vivo, ganho de peso, consumo de ração e conversão alimentar apresentaram diferenças significativas no decorrer das fases avaliadas, porém, mostraram-se semelhantes ao final do período avaliado. O desempenho dos machos apresentou superioridade em comparação com as fêmeas e os mistos. No rendimento de carcaça, não foi possível observar diferenças significativas entre as linhagens e sexagens das aves; no entanto, em alguns cortes nobres a linhagens Cobb apresentou melhores resultados.

Palavras-chave: avicultura; genética; mercado consumidor; tecnologia.

\begin{abstract}
We carried out this study to evaluate the productive performance and carcass yield of different strains and sexing of broilers. We evaluated 576 birds of Cobb, Ross, and Hubbard strains, arranged in male, female or mixed sexing, slaughtered at 45 days of age. We used a completely randomized design (CRD), in a 3 X 3 factorial (strain $\mathrm{X}$ sex), with four replicates per treatment. Body weight, weight gain, feed intake, and feed conversion showed significant differences in the course of the phases evaluated; however, they were similar at the end of the study period. Males showed superior results compared to females and mixed sexing. Carcass yield showed no significant differences among strains and sexing of birds; however, in some prime cuts, Cobb presented the best results.
\end{abstract}

Keywords: consumer market; genetics; poultry; technology. 


\section{Introdução}

O crescimento mundial ocorrido na avicultura de corte nos últimos anos representou grande importância na economia de diversos países, principalmente naqueles em que o setor agropecuário possui grande interferência econômica e social. O Brasil é o maior exportador e o segundo maior produtor de frangos de corte do mundo. Em 2015, a produção ficou em 13,14 milhões de toneladas, sendo que $32,46 \%$ foram abatidos no estado do Paraná(1). Outro dado importante é o consumo per capita que em 2015 foi de $43,2 \mathrm{~kg}^{(1)}$.

A atual crise fiscal e os problemas econômicos no país atrelados aos altos custos de produção do milho e da soja podem afetar a cadeia avícola. Apesar de o Brasil exportar para mais de 150 países, a abertura de novos mercados em países do continente asiático e africano pode ser uma alternativa para continuar e ainda aumentar sua produção ${ }^{(2)}$.

De modo importante e de forma crescente, a avicultura mundial direciona seus fundamentos a fatores cada vez mais complexos e sistêmicos, concentrando-se na busca de programas de melhoramento genético, nutrição e sanidade animal, bem como na utilização de novos equipamentos e na implantação de técnicas de manejo que possibilitam melhorias nas condições de criação. Essa preocupação tem resultado em impactos positivos nas condições produtivas, melhorando ganho de peso, conversão alimentar e otimizando espaço e tempo na produção de carne de frango ${ }^{(3)}$.

De acordo com Stringhini et al. ${ }^{(4)}$, ocorre uma contínua busca pela melhoria do material genético utilizado nas linhagens de frangos de corte em virtude da evolução e da competitividade existente na indústria avícola. Com isso, são realizadas pesquisas para identificar linhagens que apresentem características superiores em relação ao desempenho produtivo e rendimento de carcaça.

Segundo Lara et al. ${ }^{(5)}$, a linhagem Cobb apresenta o melhor desempenho produtivo devido ao melhor ganho de peso, maior rusticidade e resistência ao manejo de temperatura e alta densidade de criação. Além disso, possui alta capacidade de deposição de músculo, obtendo melhor conversão alimentar. No entanto, devido ao alto ganho de peso, sua estrutura óssea torna-se limitante, predispondo a ocorrência de problemas locomotores, menor viabilidade do lote em virtude da mortalidade por infarto e problemas de locomoção.

A linhagem Ross, de acordo com Vieira et al. ${ }^{(6)}$, apresenta desempenho produtivo semelhante à linhagem Cobb; entretanto, possui crescimento inicial inferior, com o ganho compensatório após os 21 dias de idade, obtendo alto ganho de peso final, ou seja, o peso de abate é semelhante ao das outras linhagens. Para estes mesmos autores, as aves da linhagem Ross apresentam melhor viabilidade do lote, menor possibilidade de problemas locomotores e melhor rendimento de peito ${ }^{(6)}$.

A linhagem Hubbard passou por um processo de adaptação formando um material genético que atendesse às demandas de mercado, apresentando bom ganho de peso, boa conversão alimentar e alta viabilidade. Possui grande resistência às variações de temperatura e problemas metabólicos, apresentando bom empenamento, o que possibilita menor incidência de arranhões e hematomas, além da baixa percentagem de gordura abdominal ${ }^{(7)}$. 
Comparando aves sexadas, Stringhini et al. ${ }^{(4)}$ verificaram que os machos apresentam maior peso de carcaça, melhor rendimento da carcaça eviscerada em relação ao peso vivo e de carcaça eviscerada em relação à carcaça depenada e após a sangria. $\mathrm{O}$ maior peso de carcaça, bem como o maior rendimento da carcaça dos machos, pode ser justificado pela maior percentagem de gordura apresentada pelas fêmeas, que acaba interferindo no ganho de peso e na conversão alimentar deste grupo.

Em condições semelhantes de manejo e de nutrição, o ganho de peso dos frangos de corte machos apresenta-se superior ao das fêmeas, podendo ser justificado pela melhor eficiência no aproveitamento dos alimentos, melhorando a conversão alimentar com maior deposição de tecido muscular $^{(8)}$. Diante desta situação, o objetivo deste trabalho foi avaliar o efeito da linhagem e da sexagem de frangos de corte em relação ao desempenho produtivo e ao rendimento de carcaça.

\section{Material e métodos}

O presente trabalho foi realizado no galpão experimental da Universidade Tecnológica Federal do Paraná (UTFPR), Campus Dois Vizinhos, Região Sudoeste do Paraná, no período de 04 de maio a 18 de junho de 2012.

O delineamento experimental utilizado foi inteiramente casualizado (DIC), sendo bifatorial $3 \times 3$ (linhagem x sexagem), formando nove tratamentos com quatro repetições e 16 aves por unidade experimental. As três linhagens utilizadas foram Cobb, Ross ou Hubbard e a sexagem foi macho, fêmea ou misto. Os tratamentos empregados foram: T1 - Macho Cobb; T2 - Fêmea Cobb; T3 Macho Ross; T4 - Fêmea Ross; T5 - Macho Hubbard; T6 - Fêmea Hubbard; T7 - Misto Cobb; T8 - Misto Ross; T9 - Misto Hubbard.

Foram utilizados 576 frangos de corte com peso inicial médio de 44,8 gramas e idade de matrizes de 38 e 40 semanas. Foram distribuídos em boxes de 1,32 m² (1,10 m x 1,20 m), com 16 aves cada (densidade de $12,12 / \mathrm{m}^{2}$ ), proveniente de doação de incubatório parceiro da empresa avícola e da UTFPR. As aves foram vacinadas no incubatório contra Marek, Bouba Aviária, Gumboro e Bronquite Infecciosa das galinhas.

As aves foram alimentadas com água e ração a vontade. Para o fornecimento da água foi utilizado bebedouro tipo nipple, seguindo vazão de acordo com a recomendação técnica para cada idade das aves. A ração foi fornecida em comedouros pendulares (manuais) com capacidade de $20 \mathrm{~kg}$, balanceada de acordo com as fases de desenvolvimento, utilizando-se como critério para mudança de ração a quantidade ingerida por ave. O fornecimento iniciou com Pré-Inicial (180 g/ave), Inicial (830 g/ave), Crescimento (2400 g/ave) e Final (média de 1400 g/ave). Para cada fase, as rações foram formuladas atendendo às exigências nutricionais segundo Rostagno et al. ${ }^{(9)}$

No primeiro dia, as aves ficaram expostas a 24 horas de luz. A partir do segundo dia foi iniciado o programa de luz com uma hora de escuro, aumentando gradativamente uma hora de escuro por dia, até completar 8 horas de escuro ( $9^{\circ}$ dia de idade), mantendo essa quantidade de horas de escuro até o abate. 
O controle da temperatura foi feito com o auxílio de um termohigrômetro, com aquecimento realizado por aquecedores à lenha e o resfriamento com o manejo manual das cortinas laterais do galpão, sendo observado que a menor temperatura registrada ocorreu quando as aves apresentavam 32 dias $\left(17,2^{\circ} \mathrm{C}\right)$ e a maior temperatura no dia do alojamento $\left(32,5^{\circ} \mathrm{C}\right)$. Os pintainhos foram alojados sobre cama de $7 \mathrm{~cm}$ de altura, composta de maravalha de primeira utilização, sendo desinfetados toda a estrutura e os equipamentos utilizados no trabalho.

No alojamento, todos os pintainhos foram pesados para a distribuição nos boxes. Semanalmente, foi realizada a pesagem da ração fornecida e a sobra para o cálculo do consumo semanal e diário de cada tratamento. Além disso, foi realizada a pesagem de todas as aves para cálculo do peso médio de cada uma, ganho de peso semanal e ganho de peso diário. Com o peso e o consumo de ração semanal, foi calculada a conversão alimentar semanal e aos 45 dias de idade (abate) a conversão final.

Aos 45 dias de idade todas as aves foram pesadas e posteriormente todas abatidas, sendo que cinco aves de cada boxe foram utilizadas para obtenção do rendimento de carcaça, após passarem por jejum de 6 horas de alimentação.

O rendimento de carcaça foi calculado em relação ao peso eviscerado da carcaça quente: [\%rendimento de carcaça $=$ (peso carcaça*100/peso vivo) $]$. Para obtenção do percentual de cada corte, foi utilizado o peso do corte em relação ao peso eviscerado da carcaça quente, pela seguinte equação: [\% rendimento corte $=(($ peso corte/peso eviscerado $) * 100)]$. Os cortes obtidos foram cabeça, pescoço, patas, fígado, moela, coração, gordura abdominal, coxa, sobrecoxa, asas, peito, dorso e pele. $\mathrm{O}$ rendimento de carcaça e dos cortes foi determinado segundo metodologia descrita por Mendes ${ }^{(10)}$.

Os dados foram submetidos à análise de variância (ANOVA) e as médias dos tratamentos comparadas pelo teste de Tukey a $1 \%$ ou $5 \%$ de significância, utilizando-se o programa estatístico Assistat ${ }^{(11)}$.

\section{Resultados e Discussão}

Os resultados do desempenho produtivo estão apresentados na Tabela 1. Nas primeiras semanas foi possível observar que o menor peso médio foi apresentado pela linhagem Hubbard em relação a Cobb e Ross. Houve maior ganho de peso pela linhagem Hubbard a partir dos 21 dias de idade não apresentando diferenças significativas ao final do período avaliado. Com estes dados, observou-se que as linhagens Cobb e Ross possuem maior precocidade em relação à Hubbard, que apresenta ganho de peso compensatório, aumentando significativamente seu ganho de peso a partir da quarta semana, tornando o peso vivo no abate semelhante ao das demais linhagens.

Garcia Neto \& $\operatorname{Campos}^{(7)}$ verificaram que as linhagens Ross e Hubbard aumentaram seus ganhos de peso nas últimas três semanas, igualando o peso final em função das características genéticas. Avaliando o desempenho inicial até 21 dias de idade, Marcato et al. ${ }^{(12)}$ observaram que os frangos da linhagem Cobb apresentaram maior ganho de peso do que a Ross. Para Lara et al. ${ }^{(5)}$, a linhagem 
Cobb destaca-se em função da maior capacidade de deposição de músculo (peito) e boa conversão alimentar. Porém, esse aumento no ganho de peso pode interferir no resultado final do lote, diminuindo a viabilidade em decorrência do aumento de eliminados por problemas locomotores ou morte por infarto.

Resultados de ganho de peso semelhantes foram encontrados por Vieira et al. ${ }^{(6)}$ que, avaliando diferentes linhagens, observaram maior peso inicial da Cobb, com maior ganho de peso na fase final da linhagem Ross, não apresentado diferenças ao final do período. Stringhini et al. ${ }^{(4)}$, avaliando as linhagens Cobb, Ross e Hubbard, não encontraram diferenças no peso vivo aos 45 dias de idade. Murakami et al. ${ }^{(13)}$, avaliando as mesmas linhagens, não detectaram diferenças entre Cobb e Ross.

$\mathrm{O}$ aumento no ganho de peso proporciona às aves um maior peso vivo e, com isso, é possível observar as diferenças que ocorrem entre a sexagem das aves avaliadas. Na fase inicial (até 14 dias), foi observado que não houve diferenças significativas entre machos, fêmeas e mistos. A partir da terceira semana, machos diferenciaram no ganho de peso e no peso vivo, diferenciando significativamente até o abate, o que também foi evidenciado pela sua participação nos mistos.

O maior consumo de ração dos machos a partir da quarta semana foi superior ao das fêmeas em $10,2 \%{ }^{(7)}$. Schmidt et al. ${ }^{(14)}$ encontraram efeito do sexo $(\mathrm{P}<0,01)$ em relação ao consumo de ração e ao ganho de peso, de tal forma que os machos apresentaram consumo superior em 8,18\% em relação às fêmeas e o ganho de peso superior em $9,13 \%$.

Apresentando menor peso médio e menor ganho de peso na fase inicial, é evidente o menor consumo de ração da linhagem Hubbard nesta fase, com aumento de consumo na fase final, sendo que Hubbard e Ross apresentaram, ao final, consumo de ração superior quando comparadas à Cobb. Esses resultados são semelhantes aos de Vieira et al. ${ }^{(6)}$, que encontraram maior consumo de ração para a linhagem Ross, e aos de Moreira et al. ${ }^{(15)}$, que detectaram menor consumo pela linhagem Cobb.

Na conversão alimentar, em todas as fases, não foram encontradas diferenças significativas entre as linhagens. Da mesma forma que Vieira et al. ${ }^{(6)}$, Moreira et al. ${ }^{(15)}$ não observaram diferenças ao avaliarem Cobb e Ross. Diferente de Garcia Neto e Campos ${ }^{(7)}$, que verificaram que a linhagem afetou a conversão alimentar significativamente e a linhagem Ross destacou-se de maneira positiva. Contudo, Vieira et al. ${ }^{(6)}$ obtiveram a melhor conversão alimentar pela linhagem Cobb.

Nas primeiras semanas avaliadas não foi possível observar diferenças significativas da sexagem em relação à conversão alimentar. A partir da quarta semana, os machos passaram a ter melhor aproveitamento do alimento ingerido, apresentando melhor conversão, o que se tornou constante desta fase até a data de abate, apresentando $1,61 \mathrm{~kg} / \mathrm{kg}$. Moreira et al. ${ }^{(15)}$ também observaram melhor conversão alimentar dos machos em relação às fêmeas. Em um estudo de Stringhini et al. ${ }^{(4)}$, o desempenho dos machos foi superior ao das fêmeas. Segundo os autores, as fêmeas apresentam maior quantidade de gordura corporal, interferindo no aumento da conversão alimentar e diminuição do ganho de peso das aves.

Após a concepção, a ordem de crescimento dos animais está preconizada no crescimento do tecido nervoso, tecido ósseo, tecido muscular e tecido adiposo. Como as fêmeas atingem a puberdade sexual mais precocemente do que os machos, o crescimento do tecido adiposo ocorre mais cedo, provocando a diminuição do ganho de peso em decorrência da maior utilização dos nutrientes 
ingeridos a serem destinados para o crescimento do tecido adiposo e não para o aumento do crescimento muscular.

Tabela 1. Desempenho produtivo de frangos de corte de acordo com a linhagem e a sexagem das aves

\begin{tabular}{|c|c|c|c|c|c|c|c|}
\hline & Cobb & Ross & Hubbard & Macho & Fêmea & Misto & CV \\
\hline \multicolumn{8}{|c|}{$1-7$ dias } \\
\hline Peso médio (g) & $180,87^{\mathrm{a}}$ & $178,96^{\mathrm{a}}$ & $156,12^{b}$ & $177,80^{\text {ns }}$ & $165,8^{\text {ns }}$ & $172,33^{\text {ns }}$ & 8,36 \\
\hline Ganho Peso (g) & $133,16^{\mathrm{a}}$ & $131,67^{\mathrm{a}}$ & $116,84^{b}$ & $133,43^{\text {ns }}$ & $121,22^{\text {ns }}$ & $127,02^{\text {ns }}$ & 11,4 \\
\hline Consumo Ração (kg) & $0,21^{\mathrm{a}}$ & $0,20^{\mathrm{a}}$ & $0,17^{\mathrm{b}}$ & $0,20^{\text {ns }}$ & $0,19^{\text {ns }}$ & $0,19^{\text {ns }}$ & 9,56 \\
\hline Conversão Alimentar & $1,05^{\mathrm{ns}}$ & $1,03^{\text {ns }}$ & $1,01^{\text {ns }}$ & $1,02^{\text {ns }}$ & $1,08^{\mathrm{ns}}$ & $1,02^{\text {ns }}$ & 12,51 \\
\hline \multicolumn{8}{|c|}{$7-14$ dias } \\
\hline Peso médio (g) & $469,38^{a}$ & $479,70^{\mathrm{a}}$ & $427,92^{b}$ & $478,52^{\mathrm{ns}}$ & $439,52^{\mathrm{ns}}$ & $458,96^{\mathrm{ns}}$ & 8,56 \\
\hline Ganho Peso (g) & $288,51^{a b}$ & $300,75^{\mathrm{a}}$ & $271,80^{\mathrm{b}}$ & $300,72^{\text {ns }}$ & $273,71^{\text {ns }}$ & $286,6^{\mathrm{ns}}$ & 9,82 \\
\hline Consumo Ração (kg) & $0,37^{\text {ns }}$ & $0,38^{\mathrm{ns}}$ & $0,34^{\mathrm{ns}}$ & $0,38^{\text {ns }}$ & $0,35^{\mathrm{ns}}$ & $0,37^{\text {ns }}$ & 12,06 \\
\hline Conversão Alimentar & $1,24^{\mathrm{ns}}$ & $1,22^{\mathrm{ns}}$ & $1,21^{\text {ns }}$ & $1,22^{\text {ns }}$ & $1,23^{\text {ns }}$ & $1,22^{\text {ns }}$ & 5,41 \\
\hline \multicolumn{8}{|c|}{$14-21$ dias } \\
\hline Peso médio (g) & $932,54^{\text {ns }}$ & $942,30^{\text {ns }}$ & $879,59^{\text {ns }}$ & $981,50^{\mathrm{a}}$ & $851,08^{b}$ & $921,86^{\mathrm{a}}$ & 7,26 \\
\hline Ganho Peso (g) & $463,16^{\text {ns }}$ & $462,6^{\text {ns }}$ & $451,67^{\mathrm{ns}}$ & $502,97^{\mathrm{a}}$ & $411,56^{b}$ & $462,90^{\mathrm{a}}$ & 8,63 \\
\hline Consumo Ração (kg) & $0,63^{\mathrm{ab}}$ & $0,64^{\mathrm{a}}$ & $0,59^{\mathrm{b}}$ & $0,66^{\mathrm{a}}$ & $0,58^{\mathrm{c}}$ & $0,62^{b}$ & 6,37 \\
\hline Conversão Alimentar & $1,30^{\text {ns }}$ & $1,30^{\mathrm{ns}}$ & $1,26^{\mathrm{ns}}$ & $1,27^{\text {ns }}$ & $1,31^{\text {ns }}$ & $1,29^{\text {ns }}$ & 3,38 \\
\hline \multicolumn{8}{|c|}{$21-28$ dias } \\
\hline Peso médio (g) & $1495,13^{\text {ns }}$ & $1520,15^{\mathrm{ns}}$ & $1483,40^{\text {ns }}$ & $1600,20^{\mathrm{a}}$ & $1384,64^{b}$ & $1513,87^{\mathrm{a}}$ & 6,69 \\
\hline Ganho Peso (g) & $562,59^{\text {ns }}$ & $577,83^{\text {ns }}$ & $603,84^{\text {ns }}$ & $618,70^{a}$ & $533,56^{\mathrm{b}}$ & $592,00^{\mathrm{a}}$ & 8,55 \\
\hline Consumo Ração (kg) & $0,86^{\text {ns }}$ & $0,94^{\text {ns }}$ & $0,92^{\mathrm{ns}}$ & $0,94^{\mathrm{ns}}$ & $0,87^{\text {ns }}$ & $0,92^{\mathrm{ns}}$ & 8,39 \\
\hline Conversão Alimentar & $1,39^{\text {ns }}$ & $1,43^{\text {ns }}$ & $1,37^{\mathrm{ns}}$ & $1,37^{b}$ & $1,44^{a}$ & $1,39^{\mathrm{ab}}$ & 4,73 \\
\hline \multicolumn{8}{|c|}{$28-35$ dias } \\
\hline Peso médio (g) & $2194,37^{\text {ns }}$ & $2222,21^{\mathrm{ns}}$ & $2215,54^{\text {ns }}$ & $2379,33^{a}$ & $2036,81^{c}$ & $2215,98^{b}$ & 5,06 \\
\hline Ganho Peso (g) & $699,26^{\mathrm{ns}}$ & $702,08^{\text {ns }}$ & $732,13^{\text {ns }}$ & $779,14^{\mathrm{a}}$ & $652,18^{b}$ & $702,13^{b}$ & 7,36 \\
\hline Consumo Ração (kg) & $1,28^{\text {ns }}$ & $1,29^{\text {ns }}$ & $1,26^{\mathrm{ns}}$ & $1,26^{\mathrm{ns}}$ & $1,26^{\mathrm{ns}}$ & $1,31^{\mathrm{ns}}$ & 12,83 \\
\hline Conversão Alimentar & $1,54^{\mathrm{ns}}$ & $1,56^{\mathrm{ns}}$ & $1,49^{\text {ns }}$ & $1,45^{\mathrm{b}}$ & $1,60^{\mathrm{a}}$ & $1,54^{\mathrm{ab}}$ & 6,67 \\
\hline \multicolumn{8}{|c|}{$35-42$ dias } \\
\hline Peso médio (g) & $2824,77^{b}$ & $2891,72^{\mathrm{ab}}$ & $2963,17^{a}$ & $3077,86^{\mathrm{a}}$ & $2696,37^{\mathrm{c}}$ & $2905,43^{b}$ & 4,11 \\
\hline Ganho Peso (g) & $630,40^{b}$ & $669,50^{b}$ & $747,62^{a}$ & $698,52^{\mathrm{ns}}$ & $659,55^{\text {ns }}$ & $689,45^{\mathrm{ns}}$ & 10,45 \\
\hline Consumo Ração (kg) & $1,12^{\mathrm{ns}}$ & $1,14^{\mathrm{ns}}$ & $1,31^{\mathrm{ns}}$ & $1,30^{\mathrm{a}}$ & $1,09^{\mathrm{b}}$ & $1,18^{a b}$ & 15,96 \\
\hline Conversão Alimentar & $1,58^{\mathrm{ns}}$ & $1,56^{\mathrm{ns}}$ & $1,59^{\text {ns }}$ & $1,54^{\mathrm{b}}$ & $1,61^{\mathrm{a}}$ & $1,58^{\mathrm{ab}}$ & 3,41 \\
\hline \multicolumn{8}{|c|}{$42-45$ dias } \\
\hline Peso médio (g) & $3021,62^{\text {ns }}$ & $3062,07^{\mathrm{ns}}$ & $3117,48^{\text {ns }}$ & $3309,68^{a}$ & $2804,47^{\mathrm{c}}$ & $3087,13^{b}$ & 3,54 \\
\hline Ganho Peso (g) & $196,85^{\text {ns }}$ & $170,37^{\text {ns }}$ & $154,42^{\mathrm{ns}}$ & $231,81^{\mathrm{a}}$ & $108,12^{\mathrm{b}}$ & $181,71^{\mathrm{ab}}$ & 5,35 \\
\hline Consumo Ração (kg) & $0,52^{\mathrm{b}}$ & $0,58^{\mathrm{a}}$ & $0,60^{\mathrm{a}}$ & $0,57^{\mathrm{ab}}$ & $0,54^{\mathrm{b}}$ & $0,58^{\mathrm{a}}$ & 7,40 \\
\hline Conversão Alimentar & $1,66^{\mathrm{ns}}$ & $1,69^{\text {ns }}$ & $1,67^{\text {ns }}$ & $1,61^{\mathrm{c}}$ & $1,74^{\mathrm{a}}$ & $1,68^{b}$ & 3,19 \\
\hline
\end{tabular}

Coeficiente de variaçăo (CV, \%); nível de significância (ns - não significativo).

Médias seguidas de letras diferentes na mesma linha diferem entre si pelo Teste de Tukey a 1 ou $5 \%$ de significância.

Os resultados do rendimento de carcaça e rendimentos dos cortes podem ser observados na Tabela 2. Tanto para a linhagem quanto o sexo, não foram encontradas diferenças significativas no rendimento da carcaça inteira após a evisceração. Os resultados encontrados $(80,60 \%)$ apresentamse superiores aos encontrados por Mortari et al. ${ }^{(16)}$ e Moreira et al. ${ }^{(15)}$. Almeida et al. ${ }^{(17)}$, Stringhini 
et al. ${ }^{(4)}$ e Schettino et al. ${ }^{(18)}$ não encontraram diferenças significativas no rendimento de carcaça em relação ao sexo. Garcia et al. ${ }^{(19)}$ detectaram menor rendimento da linhagem Ross e também das fêmeas em relação aos machos e a linhagem Cobb.

O rendimento de patas teve melhor resultado para a linhagem Hubbard e também com os machos e mistos. Esta variável pode ser considerada importante dependendo do mercado consumidor, pois em alguns países é considerável o consumo de patas, ocorrendo grandes importações com valores altos para patas de ótima qualidade. Stringhini et al. ${ }^{(4)}$ não observaram diferenças nos rendimentos de patas na avaliação das diferentes linhagens. Para Moreira et al. ${ }^{(15)}$, Garcia et al. ${ }^{(19)}$, Brunelli et al. ${ }^{(20)}$, Madeira et al. ${ }^{(21)}$ e Almeida et al. ${ }^{(17)}$, os machos apresentaram melhores resultados para rendimento de patas e o maior peso das patas pode ser justificado pelo maior crescimento da massa muscular neste sexo.

No rendimento das partes que compõem o sistema visceral, fígado e coração apresentaram diferenças entre as linhagens, enquanto que para sexagem, fígado, coração e moela apresentaram diferenças. Para rendimento de fígado e coração, a linhagem Ross e as fêmeas apresentaram superioridade em relação aos demais e para o rendimento de moela, mistos e fêmeas tiveram maior resultado. Com esses resultados, pode-se afirmar que as fêmeas apresentam maior percentual de conteúdo intestinal, sendo estas partes consideradas de menor interesse econômico pelo baixo valor comercial quando comparadas às partes nobres.

Tabela 2. Rendimento dos cortes (\%) de frangos de corte de acordo com a linhagem e a sexagem das aves

\begin{tabular}{lccccccc}
\hline Rendimento & Cobb & Ross & Hubbard & Macho & Fêmea & Misto & CV \\
\hline Carcaça & $80,60^{\text {ns }}$ & $80,77^{\text {ns }}$ & $81,42^{\text {ns }}$ & $81,17^{\text {ns }}$ & $80,83^{\text {ns }}$ & $80,80^{\text {ns }}$ & 1,74 \\
Pele & $2,94^{\text {ns }}$ & $3,32^{\text {ns }}$ & $3,62^{\text {ns }}$ & $3,72^{\text {ns }}$ & $3,04^{\text {ns }}$ & $3,13^{\text {ns }}$ & 13,60 \\
Patas & $3,73^{\mathrm{b}}$ & $3,78^{\mathrm{b}}$ & $4,05^{\mathrm{a}}$ & $4,13^{\mathrm{a}}$ & $3,48^{\mathrm{b}}$ & $3,94^{\mathrm{a}}$ & 6,46 \\
Fígado & $2,05^{\mathrm{b}}$ & $2,25^{\mathrm{a}}$ & $2,06^{\mathrm{b}}$ & $1,95^{\mathrm{b}}$ & $2,29^{\mathrm{a}}$ & $2,13^{\mathrm{a}}$ & 8,20 \\
Moela & $1,36^{\text {ns }}$ & $1,35^{\text {ns }}$ & $1,28^{\text {ns }}$ & $1,22^{\mathrm{b}}$ & $1,46^{\mathrm{a}}$ & $1,32^{\text {ab }}$ & 12,34 \\
Coração & $0,49^{\mathrm{b}}$ & $0,55^{\mathrm{a}}$ & $0,51^{\mathrm{ab}}$ & $0,49^{\mathrm{b}}$ & $0,53^{\mathrm{ab}}$ & $0,54^{\mathrm{a}}$ & 8,34 \\
Coxa & $12,36^{\mathrm{b}}$ & $12,30^{\mathrm{b}}$ & $12,87^{\mathrm{a}}$ & $12,69^{\text {ns }}$ & $12,39^{\text {ns }}$ & $12,45^{\text {ns }}$ & 4,60 \\
Sobrecoxa & $13,76^{\mathrm{b}}$ & $14,32^{\mathrm{a}}$ & $14,15^{\mathrm{ab}}$ & $14,61^{\mathrm{a}}$ & $13,85^{\mathrm{b}}$ & $13,78^{\mathrm{b}}$ & 3,65 \\
Asa & $12,05^{\mathrm{b}}$ & $12,25^{\mathrm{a}}$ & $12,06^{\mathrm{b}}$ & $11,95^{\mathrm{b}}$ & $12,29^{\mathrm{a}}$ & $12,13^{\mathrm{a}}$ & 8,20 \\
Peito c/ osso & $35,98^{\mathrm{a}}$ & $34,49^{\mathrm{b}}$ & $33,66^{\mathrm{b}}$ & $34,43^{\text {ns }}$ & $35,22^{\text {ns }}$ & $34,48^{\text {ns }}$ & 3,74 \\
Dorso & $16,27^{\mathrm{b}}$ & $16,89^{\mathrm{a}}$ & $17,25^{\mathrm{a}}$ & $16,94^{\mathrm{ns}}$ & $16,69^{\text {ns }}$ & $16,79^{\text {ns }}$ & 2,89 \\
Gordura ab. & $2,59^{\mathrm{a}}$ & $2,56^{\mathrm{a}}$ & $1,97^{\mathrm{b}}$ & $2,11^{\mathrm{b}}$ & $2,83^{\mathrm{a}}$ & $2,19^{\mathrm{b}}$ & 16,99 \\
\hline
\end{tabular}

Coeficiente de variação (CV, \%); nivel de significância (ns - não significativo).

Médias seguidas de letras diferentes na mesma linha diferem entre si pelo Teste de Tukey a 1 ou $5 \%$ de significância.

Para Stringhini et al. ${ }^{(4)}$, Kawauchi et al. ${ }^{(22)}$ e Almeida et al. ${ }^{(17)}$, a proporção de vísceras não apresentou diferenças em relação à sexagem das aves. Schettino et al. ${ }^{(18)}$ afirmaram que a proporção de vísceras varia de acordo com o órgão avaliado, havendo a influência da sexagem das aves. Santos et al. ${ }^{(23)}$ obtiveram maiores resultados de fígado com a linhagem Cobb e com fêmeas. Schettino et al. ${ }^{(18)}$, avaliando a sexagem e o tempo de jejum pré-abate, identificaram maior rendimento de fígado com quatro horas de jejum e com as fêmeas.

No rendimento de coração, Lara et al. ${ }^{(5)}$ não encontraram diferenças avaliando as linhagens Cobb e 
Ross. Kawauchi et al. ${ }^{(22)}$, comparando a sexagem das aves, também não encontraram diferenças significativas. O tempo de luz oferecida na fase inicial de criação pode interferir no desenvolvimento e tamanho do coração e, consequentemente, na viabilidade do lote devido à problemas cardíacos.

A linhagem Hubbard apresentou menor percentual de gordura abdominal, enquanto que as fêmeas apresentaram valores superiores na comparação do sexo. A presença de gordura abdominal na carcaça não é um fator desejado, já que a gordura abdominal não possui valor econômico e aumenta o custo de produção. De acordo com Avila et al. ${ }^{(24)}$, não há correlação significativa da gordura abdominal com o peso vivo nem com o da carcaça eviscerada. Vieira et al. ${ }^{(6)}$ e Lara et al. ${ }^{(5)}$ não encontraram diferenças entre a linhagem Cobb e Ross. Moreira et al. ${ }^{(15)}$ e Garcia et al. ${ }^{(19)}$ encontraram o maior rendimento de gordura abdominal na linhagem Ross. Para diversos autores $^{(4,17,19,25)}$, as fêmeas também apresentaram maior rendimento de gordura abdominal, sendo considerado um dos fatores que interferem na conversão alimentar pelo fato de a deposição do tecido adiposo diminuir a eficiência alimentar.

A linhagem Hubbard apresentou o maior rendimento de coxa, não havendo diferenças significativas entre o sexo. Da mesma forma, a linhagem Hubbard e Ross tiveram maiores resultados de sobrecoxas, apresentando a primeira diferença significativa em relação à Cobb. Os machos foram superiores neste corte.

Stringhini et al. ${ }^{(4)}$, Brunelli et al. ${ }^{(20)}$, Schettino et al. ${ }^{(18)}$ e Almeida et al. ${ }^{(17)}$ verificaram maior rendimento de coxa e sobrecoxas nos machos. Avila et al ${ }^{(24)}$ encontraram rendimentos parecidos para a linhagem Hubbard e as demais linhagens (Arbor Acress, Pilch e Cobb). Santos et al. ${ }^{(23)}$ e Vieira et al. ${ }^{(6)}$ encontraram os melhores rendimentos para estes cortes com a linhagem Cobb.

Como observado no rendimento de asa, a linhagem Ross apresentou diferença superior significativa em relação às demais. Na comparação do sexo, os machos apresentaram resultados inferiores, semelhantes aos resultados de Moreira et al. ${ }^{(15)}$ e Schettino et. al. ${ }^{(18)}$ e diferente dos de Stringhini et al. ${ }^{(4)}$, que encontraram o maior rendimento de asa nos machos. Garcia et al. ${ }^{(19)}$, Kawauchi et al. ${ }^{(22)} \mathrm{e}$ Almeida et al. ${ }^{(17)}$ não encontraram diferenças entre o sexo. Flemming et al. ${ }^{(8)}$, também avaliando as linhagens Cobb, Ross e Hubbard, encontraram na linhagem Ross superioridade em relação às demais. Stringhini et al. ${ }^{(4)}$, Moreira et al. ${ }^{(15)}$ e Vieira et al. ${ }^{(6)}$ não obtiveram diferenças entre as linhagens para o corte de asas.

A linhagem Cobb apresentou o menor rendimento de dorso. O rendimento deste corte não possui interesse econômico pelo fato de não ser um corte nobre e na maioria das vezes é pouco aproveitado ou até mesmo descartado totalmente para subprodutos. Moreira et al. ${ }^{(15)}$ e Schettino et al. ${ }^{(18)}$ também não encontraram diferenças entre sexo. Stringhini et al. ${ }^{(4)}$ encontraram nos machos o maior rendimento de dorso. Para Moreira et al. ${ }^{(15)}$, a linhagem Ross apresentou maior rendimento. Stringhini et al. ${ }^{(4)}$ não encontraram diferenças entre as linhagens.

A linhagem Cobb apresentou destaque no rendimento do peito, o principal corte de interesse econômico, apresentando diferença significativa em relação a Ross e Hubbard. Com relação ao sexo das aves, não houve diferença significativa. Este corte, devido à sua importância econômica, pode ser utilizado como um dos principais fatores na escolha da linhagem utilizada pelas integrações avícolas. 
Flemming et al. ${ }^{(8)}$ e Vieira et al. ${ }^{(6)}$ verificaram que a linhagem Ross foi superior em relação a Cobb e Hubbard. Já Stringhini et al. ${ }^{(4)}$ e Lara et al. ${ }^{(5)}$ não encontraram diferenças entre as linhagens Cobb e Ross. Moreira et al. ${ }^{(15)}$, avaliando machos e fêmeas das linhagens Cobb e Ross, não encontraram diferenças entre as linhagens, porém, na linhagem Cobb as fêmeas apresentaram-se superiores aos machos, semelhante aos resultados de Almeida et al. ${ }^{(17)}$. Garcia et al. ${ }^{(19)}$, Brunelli et al. ${ }^{(20)} \mathrm{e}$ Schettino et al. ${ }^{(18)}$, não encontraram diferenças entre machos e fêmeas nos trabalhos realizados.

\section{Conclusões}

O desempenho produtivo das aves recebe influência das linhagens avaliadas de acordo com a variável e o período observado; entretanto, na idade de abate, todas apresentaram resultados satisfatórios para o desempenho zootécnico que é buscado pela avicultura. O desempenho dos machos apresentou-se superior no ganho de peso e conversão alimentar.

A linhagem Cobb apresentou melhores resultados em alguns cortes, principalmente de peito; contudo, para o rendimento de carcaça, todas as linhagens mostraram bons rendimentos, não apresentando diferenças.

No presente estudo, todas as linhagens apresentaram bom rendimento produtivo e de carcaça, devendo as empresas avícolas basear-se nos critérios de mercado para a escolha de uma ou outra linhagem.

\section{Referências}

1. Associação Brasileira de Proteína Animal - ABPA. Relatório Anual 2016. Disponível em: <http://abpabr.com.br/setores/avicultura/publicacoes/relatorios-anuais>. Acesso em: 12 abr. 2017.

2. CONAB - Companhia Nacional de Abastecimento. 2016. Perspectivas agropecuárias. Brasília, v. 4, p. 1 129. Set. 2016. Disponível em: 〈http://www.conab.gov.br/detalhe.php?c=41571\&t=2\#this>. Acesso em: 12 abr. 2017.

3. Alves JMS, Martinelli O, Dewes H. Dinâmica inovativa no agronegócio: a inovação tecnológica na avicultura industrial por meio da análise de patentes. Cadernos de Ciência \& Tecnologia, Brasília. 2006;23(2/3):207-233.

4. Stringhini JH, Laboissiére M, Muramatsu K, Leandro NSM, Café MB. Avaliação do desempenho e rendimento de carcaça de quatro linhagens de frangos de corte criadas em Goiás. Revista Brasileira de Zootecnia. 2003;32(1):183-190.

5. Lara LJC, Baião NC, Rocha JSR, Lana, AMQ, Cançado SV, Fontes DO, Leite RS. Influência da forma física da ração e da linhagem sobre o desempenho e rendimento de cortes de frangos de corte. Arquivo Brasileiro de Medicina Veterinária e Zootecnia. 2008;60(4):970-978.

6. Vieira SL, Olmos AR, Berres J, Freitas DM, Coneglian JLB, Peña JEM. Respostas de frangos de corte fêmeas de duas linhagens a dietas com diferentes perfis protéicos ideais. Ciência Rural. 2007;37(6).

7. Garcia Neto M, Campos EJ. Suscetibilidade de linhagens de frangos de corte à síndrome ascítica. Pesquisa Agropecuária Brasileira. 2004;39(8):803-808. 
8. Flemming JS, Janzen SA, Endo MA. Rendimento de carcaças em linhagens comerciais de frangos de corte. Archives of Veterinary Science. 1999;4(1):61-63.

9. Rostagno HS, Albino LFT, Donzele JL et al. Tabelas Brasileiras para Aves e Suínos. Composição de alimentos e exigências nutricionais. 3.ed. Viçosa, MG: Universidade Federal de Viçosa. 2011. 252p.

10. Mendes AA, Garcia EA, Gonzales E. Efeito da linhagem sobre o rendimento de carcaça de frango de corte. Aquivo Brasileiro de Medicina Veterinária e Zootecnia. 1993;45:315-322.

11. Silva FASE, Azevedo CAV. Versão do programa computacional Assistat para o sistema operacional Windows. Disponível em: < http://www.assistat.com/indexp.html>. Acesso em 2012.

12. Marcato SM, Sakomura NK, Barbosa NA. Curvas de crescimento e da deposição de nutrientes corporais de duas linhagens de frangos de corte. Revista Brasileira de Ciência Avícola. 2006;8:167.

13. Murakami, A. E.; Watkins, S. E.; Saleh, E. A.; England, J. A.; Waldroup, P. W. Estimation of the sodium and chloride requirements for the young broiler chick. Journal of Applied Poultry Research. 1997;6:155-162.

14. Schmidt M, Gomes PC, Albino LFT, Rostagno HS, Cecon PR, Cupertino ES. Níveis Nutricionais de Cobre para Frangos de Corte Machos e Fêmeas nas Fases de Crescimento e Terminação. Revista Brasileira de Zootecnia. 2005;34(3):890-899.

15. Moreira J, Mendes AA, Roça RO, Garcia EA, Naas IA, Garcia RG, PAZ ICLA. Efeito da densidade populacional sobre desempenho, rendimento de carcaça e qualidade da carne em frangos de corte de diferentes linhagens comerciais. Revista Brasileira de Zootecnia. 2004;33(6):1506-1519.

16. Mortari AC, Rosa AP, Zanella I, Beretta Neto C, Visentini PR, Brites LBP. Desempenho de frangos de corte criados em diferentes densidades populacionais, no inverno, no sul do Brasil. Ciência Rural, Santa Maria, 2002;32(3):493-497.

17. Almeida APS, Pinto MF, Poloni LB, Ponsano EHG, Garcia Neto M. Efeito do consumo de óleo de linhaça e de vitamina E no desempenho e nas características de carcaças de frangos de corte. Arquivo Brasileiro de Medicina Veterinária e Zootecnia. 2009;61(3):698-705.

18. Schettino DN, Cançado SV, Baião NC, Lara LJC, Figueiredo TC, Santos WLM. Efeito do período de jejum pré-abate sobre o rendimento de carcaça de frango de corte. Arquivo Brasileiro de Medicina Veterinária e Zootecnia. [online]. 2006;58(5):918-924. ISSN 0102-0935.

19. Garcia RG, Mendes AA, Costa C, Paz ICLA, Takahashi SE, Pelícia KP, Komiyama CM, Quinteiro RR. Desempenho e qualidade da carne de frangos de corte alimentados com diferentes níveis de sorgo em substituição ao milho. Arquivo Brasileiro de Medicina Veterinária e Zootecnia. 2005;57:634-643.

20. Brunelli SR, Pinheiro JW, Silva CA, Fonseca NAN, Oliveira DD, Cunha GE, Souza LFA. Inclusão de farelo de gérmen de milho desengordurado na alimentação de frangos de corte. Revista Brasileira de Zootecnia. 2006;35:1349-1358.

21. Madeira LA, Sartori JR, Pizzolante CC, Saldanha ESPB; Silva MDP, Mendes AA, Takahashi SE, Solarte WVN. Morfologia das fibras musculares esqueléticas de frangos de corte de diferentes linhagens criados em sistemas de confinamento e semi confinamento. Revista Brasileira de Zootecnia. 2006;35(6):2322-2332.

22. Kawauchi IM, Sakomura NK, Barbosa NAA, Aguilar CAL, Marcato SM, Bonato MA, Fernandes JBK. Efeito de programas de luz sobre o desempenho e Rendimento de carcaça, cortes comerciais e vísceras comestíveis de frangos de corte. Arquivo Brasileiro de Medicina Veterinária e Zootecnia. 2008;24(1):059065. ISSN 0102-6380.

23. Santos AL, Sakomura NK, Freitas ER, Fortes CMLS, Carrilho ENVM, Fernandes JBK. Estudo do crescimento, desempenho, rendimento de carcaça e qualidade de carne de três linhagens de frango de corte. Revista Brasileira de Zootecnia. [online]. 2005;34(5):1589-1598. ISSN 1806-9290.

24. Avila VS, Ledur MC, Barioni Junior W, Schmidt GS, Costa CN. Pesquisa Agropecuária Brasileira. 1993;28(6):64-656.

25. Gaya LG, Mourão GB, Ferraz JBS. Aspectos genéticos quantitativos de características de desempenho, carcaça e composição corporal de frangos. Ciência Rural. 2006;36:709-716. 